
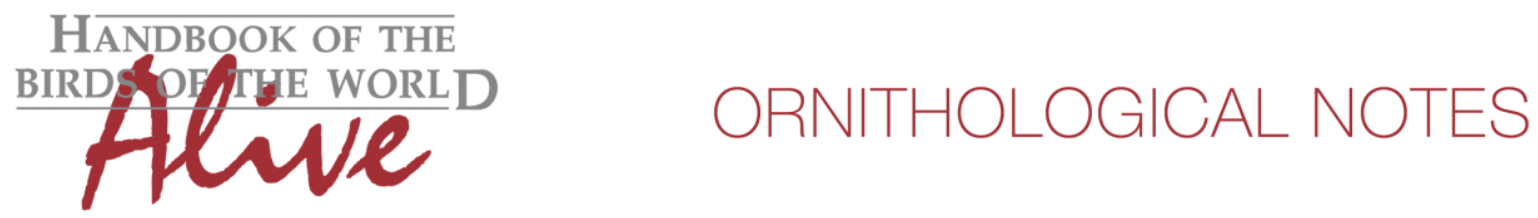

\title{
Notes on the vocalizations of Plain Flowerpecker (Dicaeum concolor)
}

Peter Boesman

In the following we briefly analyze and compare voice of the different races of Plain Flowerpecker (Dicaeum concolor). We also try to quantify the extent of any vocal differences using the criteria proposed by Tobias et al. (2010), as a support for taxonomic review. We have made use of sound recordings available on-line from Xeno Canto $(\mathrm{XC})$ and Macaulay Library (ML).

Our main interest is to compare voice of the disjunct races concolor and virescens with the remaining races. Both these races were elevated to species rank in The Ripley Guide (Rasmussen \& Anderton 2012), in part based on voice.

An overview of vocalizations:

concolor (Nilgiri)

Presumed song $(n=2)$ a fast series of short high-pitched notes
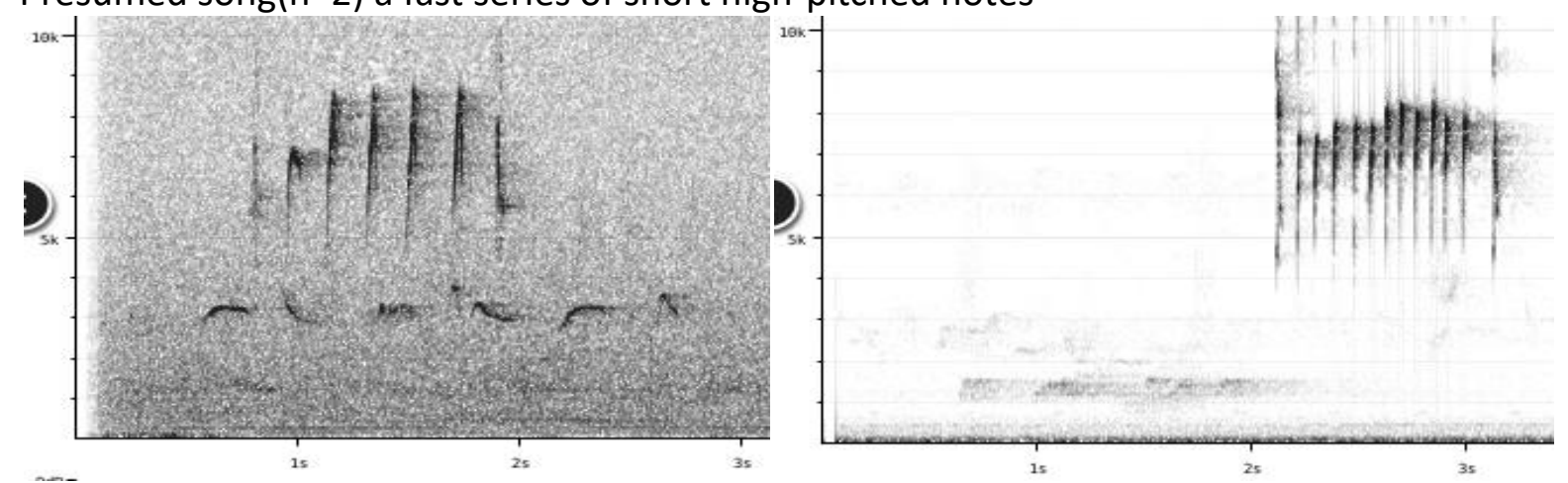

Call: a raspy short note

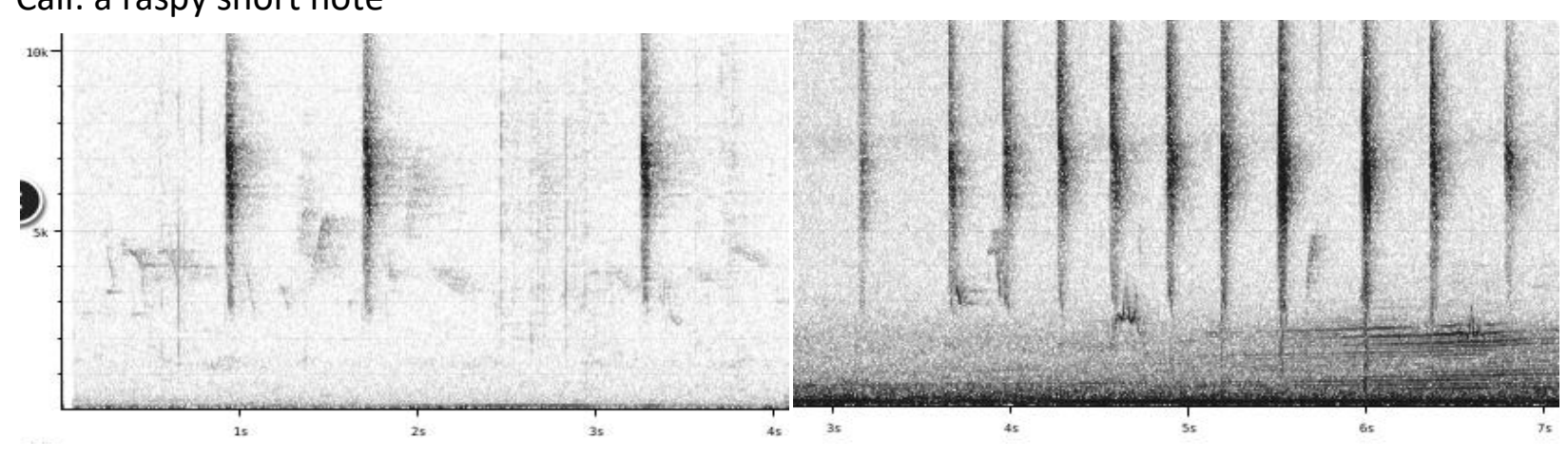

There are no recordings available on-line from the Andaman Islands (virescens).

To be compared with vocalizations of the other races (some selected examples): 


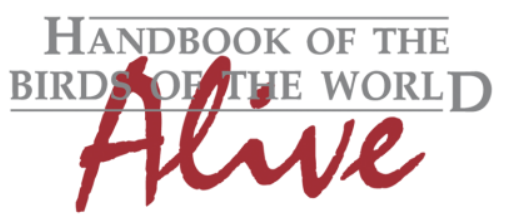

\section{ORNITHOLOGICAL NOTES}

Song: a fast series of short high-pitched notes
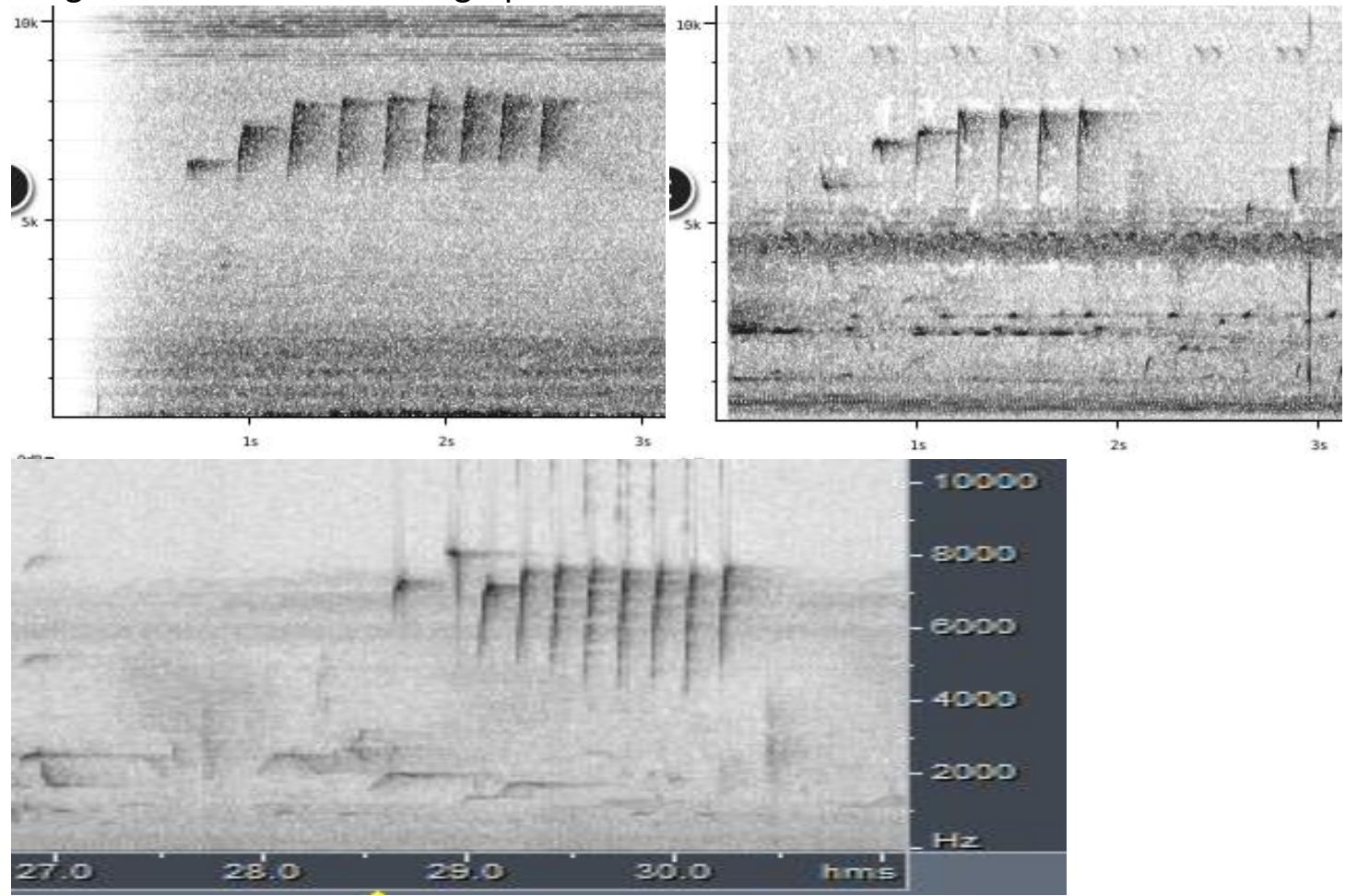

Call: very short chip notes

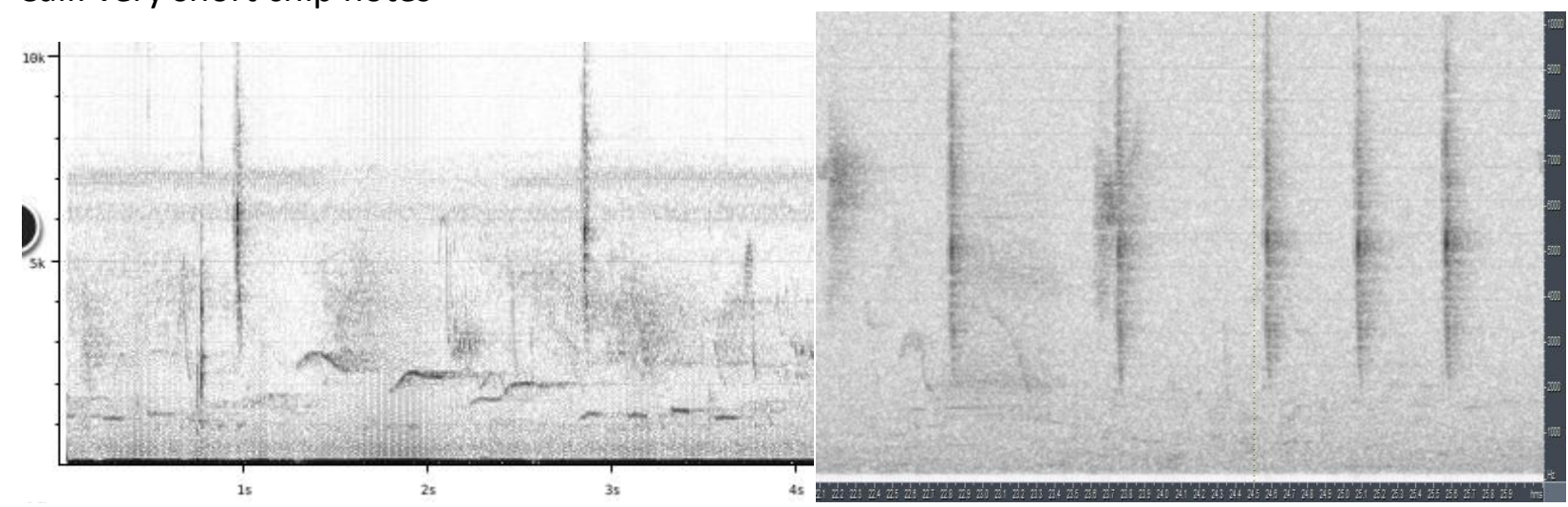

With only a few available recordings of race concolor, vocal differences are hard to assess.

Song seems to fall within the range of variability of other races.

Call of concolor sounds like "tzick" or "tzrick" while other races seemingly have a less raspy "chip".

Difference in call :

concolor

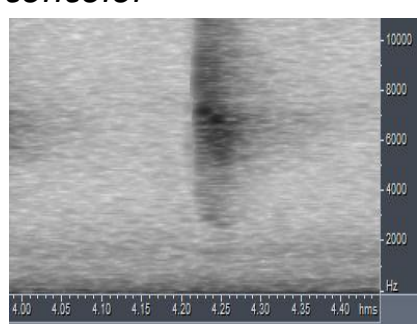

Other races: Myanmar

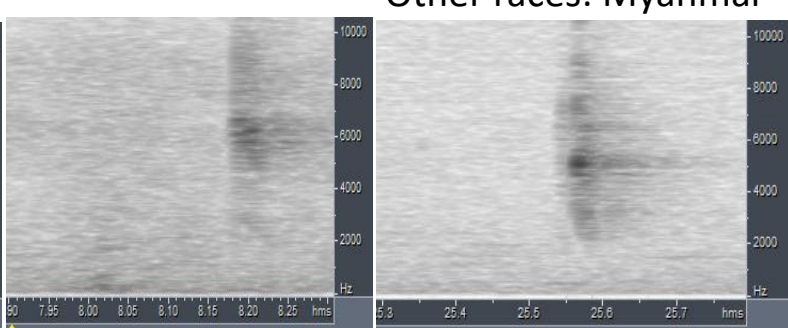

Assam

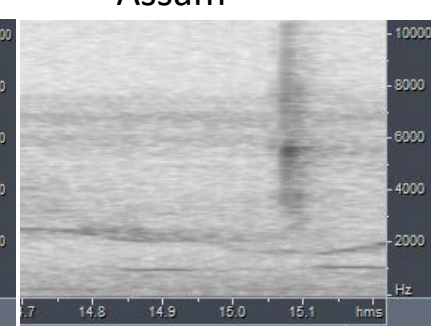



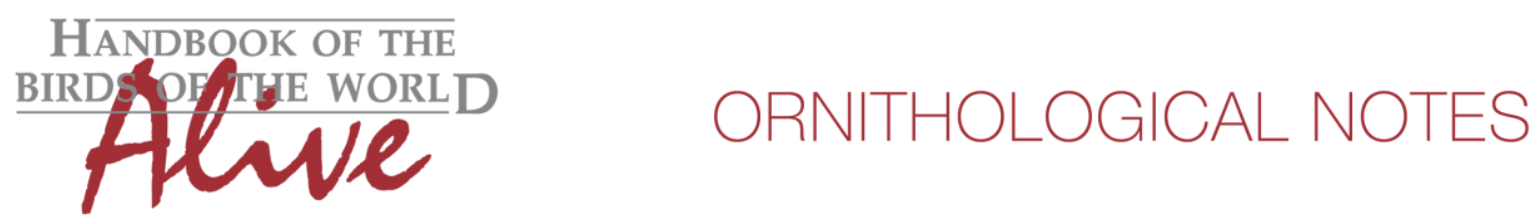

concolor has a slighty longer call note with a different shape (steeply upslurred and gently downslurred, vs hardly any slur) and base frequency apparently slightly higher-pitched. As this is not the primary vocalization, a score of 1-2 could be allowed (quantified by difference in duration and max. freq.).

As for race virescens, voice is described as markedly different in The Ripley Guide.

Song is described as a high-pitched musical "sit-sew..sit-sew...", but this may well be homologous to a vocalization type also known for other races e.g.:

N Vietnam

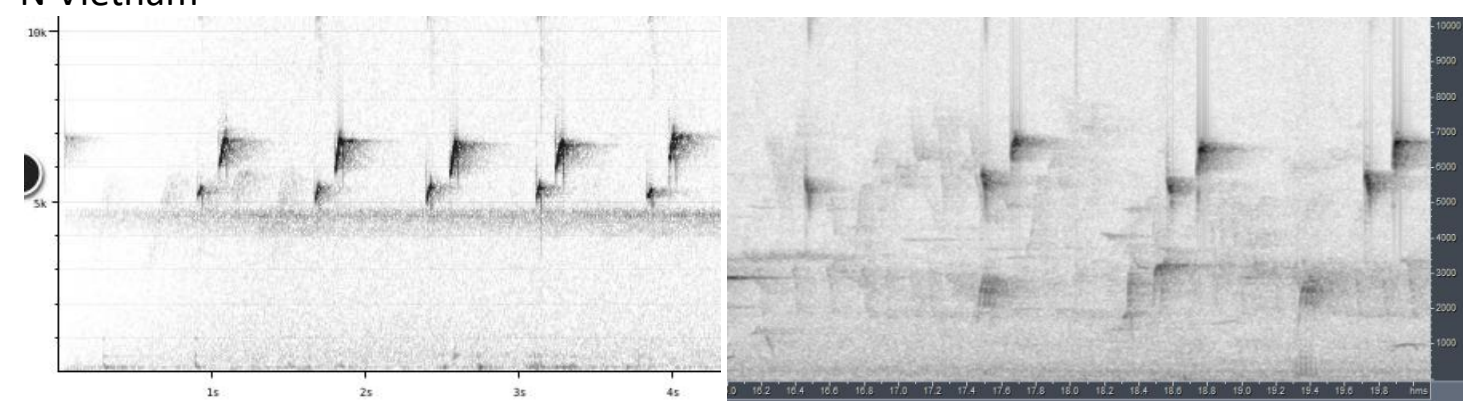

Taiwan

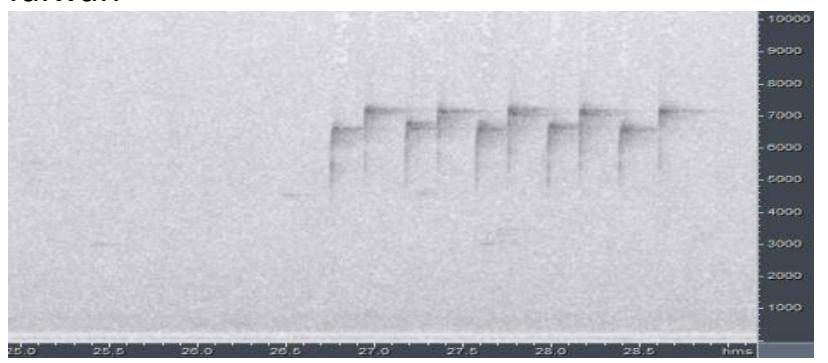

Equally so, high-pitched call notes described for virescens (pitch $5-7 \mathrm{kHz}$, duration $0.1 \mathrm{~s}$ ) may well have equivalent in other races, e.g.:
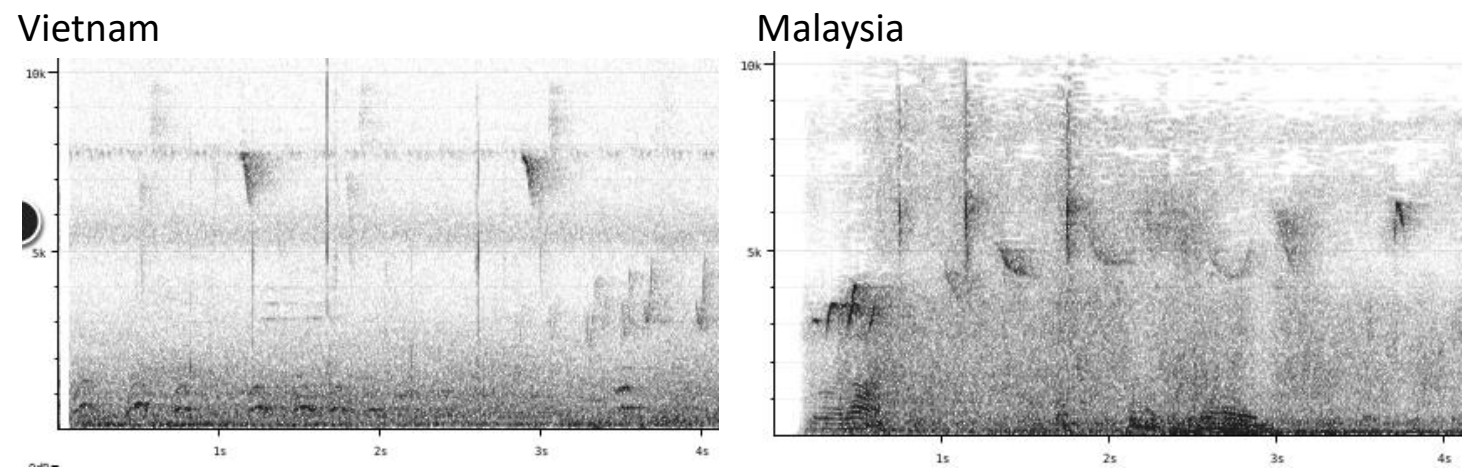

All in all, no firm conclusions can be drawn for virescens. Without a more comprehensive comparison or depiction of sonograms, the statement it is 'markedly vocally distinct' can't be verified. 

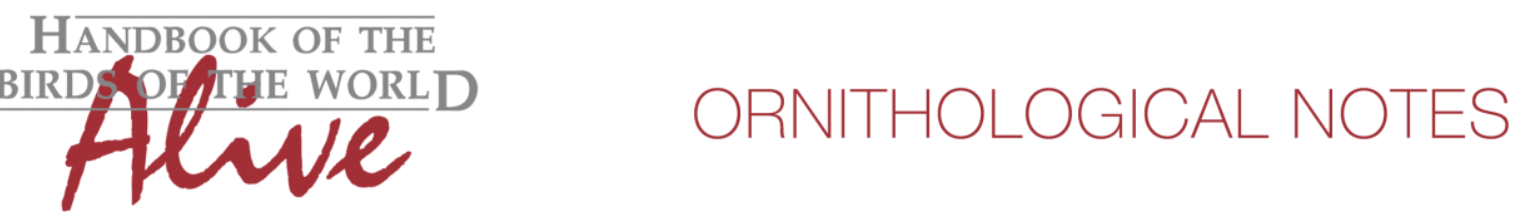

This note was finalized on 8th July 2016, using sound recordings available on-line at that moment. We would like to thank in particular the sound recordists who placed their recordings for this species on XC and ML: Mandar Bhagat, David Farrow, Stuart Fisher, Vir Joshi, Chie-Jen Ko, Pankaj Lad, Frank Lambert, Albert Lastukhin, Scott Lin, Curtis Marantz, Mike Nelson, Vivek Puliyeri, Mark Robbins, Johan Roeland, Ramit Singal, Klemens Steiof, Cynthia Su, Arnoud Van den Berg and Ding Li Yong.

\section{References}

Rasmussen, P.C. \& Anderton, J.C. (2012). Birds of South Asia: the Ripley Guide. Vols. 1-2. 2nd edition. National Museum of Natural History, Smithsonian Institution, Michigan State University \& Lynx Edicions, Washington, D.C., Michigan \& Barcelona.

Tobias, J.A., Seddon, N., Spottiswoode, C.N., Pilgrim, J.D., Fishpool, L.D.C. \& Collar, N.J. (2010). Quantitative criteria for species delimitation. Ibis 152(4): 724-746.

\section{Recommended citation}

Boesman, P. (2016). Notes on the vocalizations of Plain Flowerpecker (Dicaeum concolor). HBW Alive Ornithological Note 334. In: Handbook of the Birds of the World Alive. Lynx Edicions, Barcelona. (retrieved from http://www.hbw.com/node/1252793 on 25 October 2016). 